\title{
Treatment Strategy for Macular Edema with Ischemic Retinal Vein Occlusion
}

\section{Hidetaka Noma*}

Department of Ophthalmology, Hachioji Medical Center, Tokyo Medical University, Tokyo 193-0998, Japan

In recent years, with unhealthy eating habits and aging of society, there has been an increase of lifestyle-related diseases such as hypertension, hyper lipidemia, and diabetes, which are important risk factors for retinal vein occlusion (RVO), including branch RVO (BRVO) and central RVO (CRVO). Affecting an estimated 180,000 eyes per year in the United States, BRVO and CRVO comprise the second mostcommon type of retinal vascular disorder after diabetic retinopathy [1] BRVO accounts for approximately $80 \%$ of cases, but both types of RVO contribute to significant loss of vision, mostly as a result of macular edema $[1,2]$. The macula is the important part of the retina for detailed vision, especially the fovea that consists entirely of cones [3]. Therefore, BRVO and CRVO are potentially serious retinal diseases that can lead to severe visual impairment.

In BRVO and CRVO patients, vascular endothelial growth factor (VEGF) and several inflammatory factors have been reported to have an important role in the development of macular edema [4-6]. Several major studies, including BRAVO (Ranibizuma $B$ for the treatment of macular edema following Branch Retinal Vein Occlusion), [7] CRUISE (Ranibizumab for the treatment of macular edema after Central Retinal Vein Occlusion Study), [8] and SCORE (Standard Care vs COrticosteriod for REtinal Vein Occlusion study), [9,10] have shown that anti-VEGF therapy or intravitreal injection of triamcinolone acetonide (IVTA) improves macular edema in patients with BRVO or CRVO. However, most of the subjects of those studies had nonischemic $\mathrm{RVO}$ and the above-mentioned therapies are less effective for macular edema in patients with ischemic RVO [11,12]. This is probably because production of VEGF and inflammatory factors is higher in ischemic RVO, and because both anti-VEGF therapy and IVTA only have a temporary effect and do not improve the underlying retinal ischemia.

Unfortunately, there is no current therapy that is known to improve retinal ischemia. However, pars plana vitrectomy (PPV) was recently reported to achieve greater improvement of retinal sensitivity (measured by the Micro Perimeter 1 [13]) in ischemic RVO patients compared with nonischemic RVO patients, $[14,15]$ suggesting that PPV may indirectly alleviate retinal ischemia in patients with ischemic RVO. Elevation of the oxygen tension in the inner retina could be important for the efficacy of PPV $[16,17]$. That is, transport of oxygen from well-perfused to ischemic retinal regions by fluid currents might increase after PPV, leading to better oxygenation of the ischemic inner retina and improvement of macular edema because an increase of oxygen tension would reduce VEGF production and decrease vascular permeability. An increase of retinal oxygen tension would also improve autoregulatory arteriolar vasoconstriction and reduces pressure in the retinal capillaries and venules. When water flux from the vascular compartment to the tissue compartment decreases, edema will improve according to Starling's law. PPV seems to achieve long-term elevation of the oxygen tension in the inner retina. This surgical procedure may reduce the intraocular levels of various inflammatory factors along with VEGF, [18] which could be another mechanism leading to the alleviation of macular edema. In short, an increase of inner retinal oxygen tension after PPV could restore photoreceptor cell function, resulting in improvement of retinal sensitivity, with a better response of retinal sensitivity in patients who have ischemic RVO than in those with no ischemic RVO. In contrast, it has been reported that there was no significant difference in the trend profile of retinal sensitivity between patients with nonischemic and ischemic BRVO after IVTA [19]. Therefore, if RVO patients have severe retinal ischemia, PPV should be considered to improve retinal sensitivity rather than antiVEGF therapy or IVTA. However, PPV does not completely abolish retinal ischemia. In the future, more effective medical treatment for retinal ischemia is needed, because ischemic RVO not only causes macular edema but also vitreous hemorrhage and rubeotic glaucoma, which are associated with a risk of blindness.

\section{References}

1. Klein R, Moss SE, Meuer SM, Klein BE (2008) The 15-year cumulative incidence of retinal vein occlusion: the Beaver Dam Eye Study. Arch Ophthalmol 126: 513-518.

2. Campochiaro PA, Heier JS, Feiner L, Gray S, Saroj N et al. (2010) Ranibizumab for macular edema following branch retinal vein occlusion: six-month primary end point results of a phase III study. Ophthalmology 117: 1102-1112.

3. Hogan MJ, Alvarado JA (1971) Weddell JE: Histology of the Human Eye: An Atlas and Textbook, Philadelphia, Saunders 492

4. Noma H, Funatsu $H$, Yamasaki M, Tsukamoto $H$, Mimura $T$, et al. (2005) Pathogenesis of macular edema with branch retinal vein occlusion and intraocular levels of vascular endothelial growth factor and interleukin-6. Am J Ophthalmol140: 256-261.

5. Noma H, Funatsu H, Mimura T, Harino S, Hori S (2009) Vitreous levels of interleukin-6 and vascular endothelial growth factor in macular edema with central retinal vein occlusion. Ophthalmology 116: 87-93.

6. Noma H, Mimura T, Eguchi S (2013) Association of inflammatory factors with macular edema in branch retinal vein occlusion. JAMA Ophthalmol 131: 160-165.

7. Brown DM, Campochiaro PA, Bhisitkul RB, Ho AC, Gray S, et al. (2011) Sustained Benefits from Ranibizumab for Macular Edema Following Branch Retinal Vein Occlusion: 12-Month Outcomes of a Phase III Study. Ophthalmology 118: 1594-1602.

8. Campochiaro PA, Brown DM, Awh CC, Lee SY, Gray S, et al. (2011) Sustained benefits from ranibizumab for macular edema following central retinal vein occlusion: twelve-month outcomes of a phase III study. Ophthalmology 118: 2041-2049.

9. Ip MS, Scott IU, VanVeldhuisen PC, Oden NL, Blodi BA, et al. (2009) A randomized trial comparing the efficacy and safety of intravitreal triamcinolone with observation to treat vision loss associated with macular edema secondary to central retinal vein occlusion: the Standard Care vs Corticosteroid for Retinal Vein Occlusion (SCORE) study report 5. Arch Ophthalmol 127: 1101-1114.

*Corresponding author: Hidetaka Noma, MD, Ph.D, Department of Ophthalmology, Hachioji Medical Center, Tokyo Medical University, 1163Tatemachi, Hachioji, Tokyo 193-0998, Japan, Tel: +81-42-665-5611; Fax: +81-42-665-1796; E-mail: noma-hide@umin.ac.jp

Received April 25, 2013; Accepted April 27, 2013; Published April 29, 2013 Citation: Noma H (2013) Treatment Strategy for Macular Edema with Ischemic Retinal Vein Occlusion. J Vasc Med Surg 1: e103. doi:10.4172/23296925.1000e103

Copyright: (c) 2013 Noma H. This is an open-access article distributed under the terms of the Creative Commons Attribution License, which permits unrestricted use, distribution, and reproduction in any medium, provided the original author and source are credited. 
Citation: Noma H (2013) Treatment Strategy for Macular Edema with Ischemic Retinal Vein Occlusion. J Vasc Med Surg 1: e103. doi:10.4172/2329$6925.1000 \mathrm{e} 103$

Page 2 of 2

10. Scott IU, Ip MS, VanVeldhuisen PC, Oden NL, Blodi BA, et al. (2009) A randomized trial comparing the efficacy and safety of intravitreal triamcinolone with standard care to treat vision loss associated with macular Edema secondary to branch retinal vein occlusion: the Standard Care vs Corticosteroid for Retinal Vein Occlusion (SCORE) study report 6. Arch Ophthalmol 127: 11151128.

11. Jonas JB, Akkoyun I, Kamppeter B, Kreissig I, Degenring RF (2005) Branch retinal vein occlusion treated by intravitreal triamcinolone acetonide. Eye (Lond) 19: 65-71.

12. Kriechbaum K, Michels S, Prager F, Georgopoulos M, Funk M, et al. (2008) IntravitrealAvastin for macular oedema secondary to retinal vein occlusion: a prospective study. Br J Ophthalmol 92: 518-522.

13. Noma H, Funatsu H, Mimura T, Harino S, Shimada K (2011) Functionalmorphologic correlates in patients with branch retinal vein occlusion and macular edema. Retina 31: 2102-2108.

14. Noma H, Mimura T, Shimada K (2013) Changes of macular sensitivity and morphology after pars planavitrectomy for macular edema with central retinal vein occlusion: a case series. BMC Ophthalmol 13: 2 .

15. Noma H, Shimada K, Mimura T (2013) Influence of retinal ischemia on macular function after pars planavitrectomy for macular edema with branch retinal vein occlusion. Int Ophthalmol in press.

16. Stefansson E (2006) Ocular oxygenation and the treatment of diabetic retinopathy. Surv Ophthalmol 51: 364-380.

17. Stefansson E, Novack RL, Hatchell DL (1990) Vitrectomy prevents retinal hypoxia in branch retinal vein occlusion. Invest Ophthalmol Vis Sci 31: 284-289.

18. Noma H, Funatsu H, Mimura T, Eguchi S, Shimada K (2011) Visual prognosis and vitreous molecules after vitrectomy for macular edema with branch retinal vein occlusion. Clin Ophthalmol 5: 223-229.

19. Noma H, Funatsu H, Mimura T, Shimada K (2012) Macular sensitivity and morphology after intravitreal injection of triamcinolone acetonide for macular edema with branch retinal vein occlusion. Retina 32: 1844-1852. 